\title{
Do rats prefer water, near beer, or beer with ethanol?
}

\author{
W. MILES COX \\ Richard L. Roudebush Veterans Administration Medical Center \\ Indiana University School of Medicine, Indianapolis, Indiana \\ and \\ JOHN E. MERTZ \\ University of Illinois, Urbana, Illinois
}

\begin{abstract}
Preference of 11 female albino rats for water or beer containing varying amounts of ethanol was tested for $12 \mathrm{~h}$ daily across five phases, each lasting 15 days. During Phase 1 , the animals had free access to beer containing 3.2\% ethanol, beer without ethanol (near beer), and water. During Phases 2, 3, and 4, they had free access to $3.2 \%$ beer and water, $4.5 \%$ beer and water, and $10 \%$ beer and water, respectively. During Phase 5, they again had 3.2\% beer, near beer, and water. Between phases, there were 5 days of baseline water consumption. During Phases 1 and $5,3.2 \%$ beer was preferred over water, and near beer was overwhelmingly preferred over the other two fluids. In fact, the volume of near beer consumed during Phases 1 and 5, respectively, was 5.2 and 3.3 times the volume of water consumed at baseline. During Phase 2, 3.2\% beer was preferred to water, and during Phase $3,4.5 \%$ beer was preferred to water. Only when the ethanol concentration reached $10 \%$, during Phase 4 , was water preferred to beer.
\end{abstract}

Prior studies of rats' voluntary consumption of alcohol have found that rats generally prefer alcoholic solutions containing low concentrations of alcohol over water. (Meisch, 1977; Myers \& Veale, 1972; Wallgren \& Barry, 1970). When both water and an alcoholic solution are available, the proportion of alcoholic solution consumed to total fluid consumed generally decreases progressively as the volume of alcohol in the solution rises above $7.5 \%$ (Wallgren \& Barry, 1970).

From these studies, it is not clear if rats reject solutions with higher alcohol concentrations because of their aversive gustatory properties, their aversive pharmacological effects, or a combination of these factors. Nevertheless, we know that the taste qualities of alcoholic beverages do affect rats' readiness to consume them. For example, Mendelson and Mello (1964) found that although rats preferred low-concentration ethanol solutions over water, they preferred water over bourbon whiskey that contained the same concentration of alcohol as the ethanol solutions. Moreover, alcoholic solutions are consumed in greater quantities if they are sweetened with saccharin (Eriksson, 1969) or sucrose (Cox, 1981; Rodgers \& McClearn, 1964). In addition, when procedures are used to dull or eliminate rats' sensitivity to taste or smell, the rats consume solutions containing greater concentrations of alcohol than they otherwise consume (Lester, 1966).

The authors thank Ernest D. Kemble for his comments on the manuscript. J. E. Mertz is associated with the Department of Chemistry, University of Illinois. Requests for reprints should be sent to W. M. Cox, Psychology Service (116B), Veterans Administration Medical Center, 1481 West 10th Street, Indianapolis, IN 46202
In the present study, we investigated rats' readiness to drink "near beer," an alcohol-free beverage that is indistinguishable from "regular" beer to humans (Cox \& Klinger, 1983). Although near beer may contain traces of ethanol (legal maximum $=.5 \%$ ), the typical alcoholic content is at or near zero. Thus, rats' readiness to drink near beer can be investigated apart from their readiness to drink ethanol per se. Several previous studies observing rats' ad-lib consumption of beer with ethanol (Berman \& Cannon, 1974; Burch, Tusi, \& Harb, 1973; McDonough, Gill, \& Nielson, 1975; Richter, 1953) have found that they consume large quantities, often exceeding the volume of water that they consume. However, in these studies, the beer always contained substantial amounts of ethanol (3\%, $5 \%$, or $10 \%)$.

We first tested rats' relative preference for three fluids: water, near beer, and near beer with $3.2 \%$ ethanol added. In successive phases of the experiment, we determined the animals' preference for water versus near beer containing $3.2 \%, 4.5 \%$, and $10 \%$ ethanol. In the final phase of the experiment, we again tested preference for water, near beer, and near beer with $3.2 \%$ ethanol to see how preference might have changed as a result of the interpolated experience with the near beer containing varying concentrations of ethanol.

\section{METHOD}

\section{Subjects}

The subjects were 11 female albino rats purchased from the Holtzman Company, Madison, Wisconsin. They were 106 days old at the beginning of testing. 


\section{Apparatus}

Throughout the experiment, the animals were housed and tested in individual home cages to which $100-\mathrm{ml}$ graduated drinking tubes could be attached to the outside of the front walls. Each tube stopper contained a steel ball to prevent leakage.

\section{Beverages}

The near beer used in this study was Schmidt Select. We decarbonated the beer by placing it in a large container and shaking it vigorously until the carbonation had dissipated. For the beer-with-ethanol fluid conditions, $95 \%$ ethyl alcohol was added to the decarbonated near beer to bring the alcoholic content to the desired level. The percentage of ethanol concentration was based on volume of ethanol per volume of total fluid $(\mathrm{v} / \mathrm{v})$. All fluids (beer and water) were prepared $2 \mathrm{~h}$ prior to being administered to the animals and were refrigerated at approximately $45^{\circ} \mathrm{F}$ until the time of administration. Refrigeration was necessary to prevent coagulation of the starches in the beer. ${ }^{1}$

\section{Procedure}

The experiment was divided into five phases, each of which lasted 15 days. During each phase, the animals were exposed to the fluids for $12 \mathrm{~h}$ daily, from 8:00 a.m. to 8:00 p.m. The tubes were checked periodically throughout the day, and if it appeared that a tube would be emptied, the amount that had been consumed from it was recorded, and the tube was refilled. Again, at the end of each 12-h period, the amount consumed from each tube was recorded. Throughout the experiment, the rats had an ad-lib supply of Purina Lab Chow.

During Phase 1, the animals had free access to three fluids: tap water, near beer, and near beer with $3.2 \%$ ethanol (comparable to "weak", beer sold in the United States). The position of the three fluids (right, middle, left) was balanced across animals, and fluid position was systematically varied on each test day. During Phases 2,3 , and 4, the animals had free access to two fluids: tap water and beer with ethanol. During Phase 2, the beer contained 3.2\% ethanol; during Phase 3, the near beer contained $4.5 \%$ ethanol (comparable to "strong" beer sold in the United States); and during Phase 4, it contained $10 \%$ ethanol (a concentration typically rejected by rats that also have water available to drink). During each of these three phases, each animal's two tubes were alternated daily in a repetitive $A B B A B A A B$ manner. On any given day, half of the animals had beer in one position, and the other half had water in that position. During Phase 5, the same procedure was followed that had been used during Phase 1. Between phases, there was a 5-day interval during which the animals had daily $12-\mathrm{h}$ access to tap water from a single tube.

\section{RESULTS}

Mean total daily water and beer consumption during the five phases of the experiment and the interpolated baselines are shown in Figure 1.

Here we see an overwhelming preference for near beer during Phase 1. This preference was quite apparent at the beginning of Phase 1, but with continued exposure the rats consumed even greater quantities of near beer. By contrast, very small quantities of both water and the beer containing $3.2 \%$ ethanol were consumed. The average volume consumed of the latter two fluids remained constant during Phase 1 , with more $3.2 \%$ beer than water being consumed. Analysis of variance confirmed the statistical reliability of these observations. The effects of beverage $[\mathrm{F}(2,20)=63.64, \mathrm{p}<.001]$ and days $[\mathrm{F}(14,140)=4.35, \mathrm{p}<.001]$ and the beverage $\times$ days interaction $[F(28,280)=4.34, p<.001]$ were highly significant. The two follow-up comparisons involving near beer yielded $F$ values similar to those from the overall analysis, and the comparison of water and $3.2 \%$ beer indicated a significant effect for beverage $[F(1,10)=10.48$, $\mathrm{p}<.01]$. Comparison of fluid consumption during Phase 1 with baseline water consumption following Phase 1 indicates that the rats drank far more fluid during Phase 1 , when near beer was available, than they drank water during baseline. In fact, total fluid consumption was 5.6 times greater during Phase 1 than during baseline. All comparisons of Phase 1 and baseline fluid consumption were highly significant.

Inspection of the fluid consumption during Phase 2, when only water and $3.2 \%$ beer were available, indicates

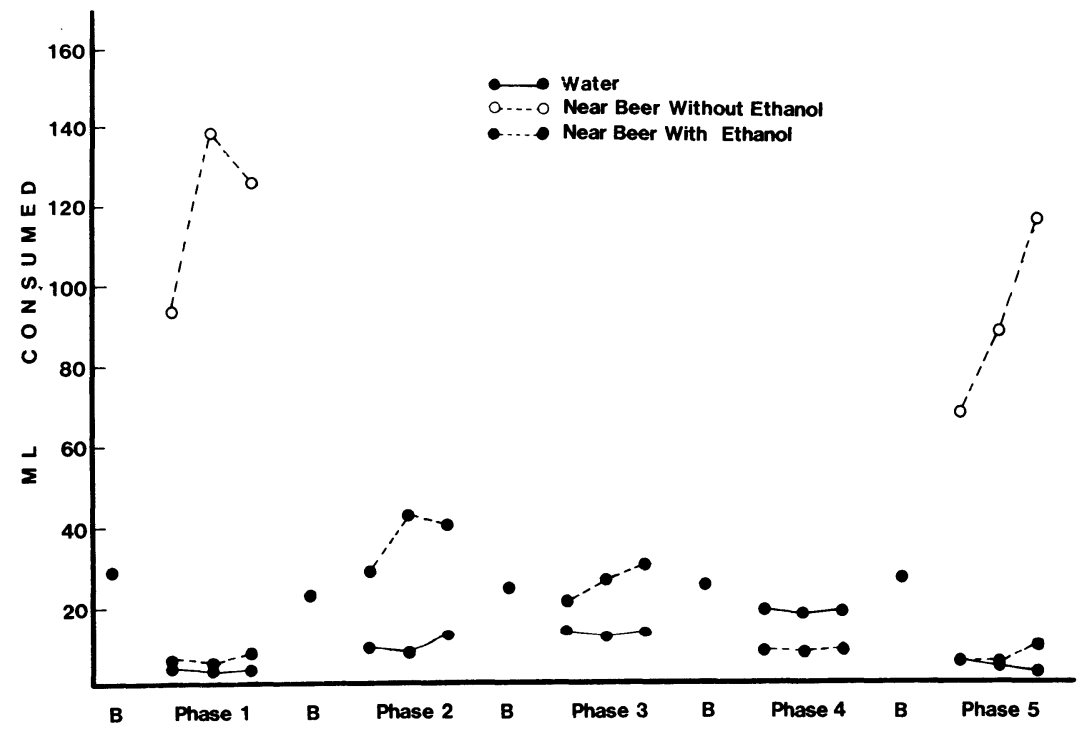

Figure 1. Mean total fluid consumption during five phases and five baselines. Each 15day phase is collapsed into three 5-day blocks. 
that the rats showed a marked preference for the $3.2 \%$ beer. This preference was strong at the beginning of the phase and persisted throughout. Analysis of variance indicated significant effects of beverage $[\mathrm{F}(1,10)=51.17$, $\mathrm{p}<.001]$ and days $[\mathrm{F}(14,140)=2.93, \mathrm{p}<.001]$, but no beverage $\times$ days interaction $[\mathrm{F}(14,140)=1.57$, $\mathrm{p}>$.09]. Comparison of the results from Phases 1 and 2 indicates large and statistically significant increases in consumption of both water and $3.2 \%$ beer from Phase 1 to Phase 2. Nevertheless, the amount of $3.2 \%$ beer consumed during Phase 2 remained significantly below the amount of near beer consumed during Phase 1. Comparison of the fluid consumption during Phase 2 with baseline water consumption just prior to Phase 2 indicates that significantly more $3.2 \%$ beer was consumed during Phase 2 than water during baseline but that significantly less water was consumed during Phase 2 than during baseline.

Inspection of the data from Phase 3, when water and $4.5 \%$ beer were consumed, indicates a developing preference for the $4.5 \%$ beer during Phase 3 . Initially, the animals drank equal amounts of the two fluids, but their consumption of $4.5 \%$ beer progressively increased until a marked preference for it was apparent at the conclusion of Phase 3. Analysis of variance confirmed that the effects of beverage $[\mathrm{F}(1,10)=10.91, \mathrm{p}<.008]$ and days $[\mathrm{F}(14,140)=5.19, \mathrm{p}<.001]$ and the beverage $\times$ days interaction $[\mathrm{F}(14,140)=2.84, \mathrm{p}<.001]$ were highly significant. Comparison of water and beer consumption in Phases 2 and 3 indicates a significant decrease in the amount of beer consumed from Phase 2 to Phase 3 and a significant increase in the amount of water consumed. Furthermore, water consumption during Phase 3 was significantly less than water consumption during the prephase baseline, and the amount of $4.5 \%$ beer consumed during Phase 3 was comparable to the amount of water consumed during the prephase baseline.

Fluid consumption during Phase 4, when the rats drank water and $10 \%$ beer, indicates a consistent preference of water throughout this phase. Analysis of variance indicated a significant effect for beverage $[\mathrm{F}(1,10)=23.19$, $\mathrm{p}<.001]$, but no effect for days $[\mathrm{F}(14,140)=1.12$, $\mathrm{p}>.34]$ and no beverage $x$ days interaction $(F<1.0)$. There was a significant decrease in the volume of $4.5 \%$ beer consumed during Phase 3 to the volume of $10 \%$ beer consumed during Phase 4 and a significant increase in the volume of water consumed from Phase 3 to Phase 4. In addition, water and beer consumption during Phase 4 were each significantly less than water consumption during the prephase baseline.

Fluid consumption during Phase 5 indicates a pattern similar to that observed during Phase 1 . That is, the rats showed a marked preference for near beer, a preference that was apparent at the beginning of Phase 5 but became even more pronounced during the course of Phase 5 . Small amounts of both water and $3.2 \%$ beer were con- sumed during Phase 5, but more $3.2 \%$ beer than water was consumed. Analysis of variance indicated that the effects of beverage $[F(2,20)=58.65, p<.001]$ and days $[\mathrm{F}(14,140)=11.90, \mathrm{p}<.001]$ and their interaction $[F(28,280)=8.63, p<.001]$ were highly significant. Follow-up comparisons involving near beer yielded $F$ values similar to those from the overall analysis, and comparison of $3.2 \%$ beer and water consumption indicated that significantly more $3.2 \%$ beer than water was consumed $[\mathrm{F}(1,10)=5.59, \mathrm{p}<.04]$. No reliable differences in beverage consumption were found between Phase 1 and Phase 5.

Finally, it is interesting to note that as the concentration of ethanol in the beer was progressively increased across successive phases, the animals did not adjust their intake of the alcoholic fluids in such a manner that they consumed constant amounts of alcohol across phases. Instead, the average daily volume of absolute alcohol consumed progressively decreased from $1.27 \mathrm{ml}(3.2 \%)$ to $1.18 \mathrm{ml}(4.5 \%)$ to $.87 \mathrm{ml}(10 \%)$ as the concentration of ethanol increased.

\section{DISCUSSION}

When the three fluids-water, near beer, and beer with ethanolwere available, the animals almost totally rejected water and beer with ethanol in preference for near beer. In addition, when near beer was available, the rats dramatically increased their total fluid consumption over what it was when only water was available to drink. We saw, in fact, that the volume of near beer consumed was several times the volume of water consumed at baseline.

Although the rats' consumption of near beer was reduced substantially when ethanol was added, the preference for beer over water remained clear-cut when the beer contained $3.2 \%$ or $4.5 \%$ ethanol. Only when the concentration of ethanol reached $10 \%$ did the rats reject beer in preference for water. This finding is consistent with previous studies showing that ethanol preference by rats disappears when concentrations approximate $10 \%$.

The rats' overwhelming preference for near beer in this experiment apparently was due to its gustatory properties. Since the rats had an adlib supply of food throughout the experiment, it is unlikely that they consumed near beer for its nutritional value. However, their enormous intake of beer was drastically reduced when even $3.2 \%$ ethanol was added, and intake of beer diminished progressively as the concentration of ethanol was increased still further. The taste and/or pharmacological effects of the ethanol itself apparently were aversive, and the aversion was strong enough to counteract the extreme preference for near beer.

The fact that the rats consumed near beer in such enormous quantities suggests that near beer would be an extremely potent reinforcer. Near beer, in fact, would seem to be ideal to use as a high-quality liquid reinforcer in future studies.

\section{REFERENCES}

Berman, R. F., \& Cannon, D. S. (1974). The effect of prior ethanol experience on ethanol-induced saccharin aversions. Physiology \& Behavior, 12, 1041-1044.

BurCh, G. E., TuSI, C. Y., \& HARB, J. M. (1973). The influence of quantity of beer consumed on the myocardium of mice. Journal of Pathology, 109, 163-167. 
Cox, W. M. (1981). Simultaneous incentive contrast effects with alcoholic and nonalcoholic beverages as the discriminanda for reward magnitude. Physiological Psychology, 9, 276-280.

Cox, W. M., \& KLINGER, E. (1983). Discriminability of regular, light, and alcoholic and nonalcoholic near beer. Journal of Studies on Alcohol, 44, 494-498.

ERIKSSON, K. (1969). Factors affecting voluntary alcohol consumption in the albino rat. Annales Zoologici Fennici, 6, 227-265.

LESTER, D. (1966). Self-selection of alcohol by animals, human variation, and the etiology of alcoholism. Quarterly Journal of Studies on Alcohol, 27, 395-438.

McDonough, J. H., Gill, J. H., \& Nielson, H. C. (1975). Impairment of fixed-interval responding during chronic alcohol drinking in rats. Physiological Psychology, 3, 417-421.

MEISCH, R. A. (1977). Ethanol self-administration: Infrahuman studies. In T. Thompson and P. B. Dews (Eds.). Advances in behavioral pharmacology. Vol. 1. New York: Academic Press.

Mendelson, J. H., \& Mello, N. K. (1964). Ethanol and whiskey drinking patterns in rats under free-choice and forced-choice conditions. Quarterly Journal of Studies on Alcohol, 25, 1-25.

Myers, R. D., \& VeAle, W. L. (1972). The determinants of alcohol preference in animals. In B. Kissin and H. Begleiter (Eds.). The biology of alcoholism. Vol. 2. New York: Plenum Press.

RICHTER, C. P. (1953). Alcohol, beer and wine as food. Quarterly Journal of Studies on Alcohol, 14, 525-539.

Rodgers, D. A., \& MCClEARN, G. E. (1964). Sucrose versus ethanol appetite in inbred strains of mice. Quarterly Journal of Studies on Alcohol, 25, 26-35.
WAllgren, H., \& BARRY, H., III. (1970). Actions of alcohol (Vol. 2) Amsterdam: Elsevier.

\section{NOTE}

1. Prior to the beginning of the experiment proper, we took baseline measurements and identified some difficulties in administering beer to animals. First, for 4 days, the animals had ad-lib access to plain tap water from a single drinking tube for $24 \mathrm{~h}$ daily. On the following 13 days, the animals were exposed to tubes containing water, carbonated near beer, and carbonated beer with $3.2 \%$ ethanol for $24 \mathrm{~h}$ daily. The tubes were alternated in the manner described below for Phases 1 and 5 of the experiment proper. During this time, we found that the carbon dioxide in the beer pressurized the drinking tubes, causing considerable leakage and hence inaccurate measurements of the amount of beer consumed. Accordingly, in the experiment proper, we decarbonated the beer in the manner described above. We also found that animals consume such large quantities of near beer that they often completely consume the contents of $100-\mathrm{ml}$ drinking tubes before $24 \mathrm{~h}$ have elapsed. Therefore, since in the present experiment we were primarily interested in animals' preferences for various fluids instead of total fluid consumption in $24 \mathrm{~h}$, we used 12-h exposure intervals.

(Manuscript received for publication August 6, 1984.) 